topical use are substantially higher than those achieved by using other forms of administration, and thus there is a good chance of eradicating the infection. If ciprofloxacin or ofloxacin fails, parenteral treatment with ceftazidime or imipenem can be used. ${ }^{12}$

Until topical ciprofloxacin is commercially available its use will remain restricted in the United Kingdom. Guidelines should be issued for the appropriate use of the drug in chronic otitis media with perforated eardrums, and its introduction for treating chronic otitis externa as well as its use in children should also be considered.

S Ghosh senior house officer

A Panarese specialist registrar

A J Parker consultant

P D Bull consultant ENT surgeon

Department of ENT, Royal Hallamshire Hospital, Sheffield S10 2JF

1 Acuin J, Smith A, Mackenzie I. Interventions for chronic suppurative otitis media. In: Cochrane Collaboration. Cochrane Library. Issue 4. Oxford: Update Software, 1999
2 Altuntas A, Aslan A, Eren N, Unal A, Nalco Y. Susceptibility of microorganisms isolated from chronic suppurative otitis media to ciprofloxacin. Eur Arch Otorhinolaryngol 1996;253:364-6.

3 Browning GG. Specific management of external and middle ear conditions. In: Clinical otology and audiology. 2nd ed. Oxford: ButterworthHeinemann, 1998:997-118.

4 Bath AP, Walsh RM, Bance ML, Rutka JA. Ototoxicity of topical gentamicin preparations. Laryngoscope 1999:109:1088-93.

5 Marais J, Rutka JA. Ototoxicity and topical eardrops. Clin Otolaryngol Allied Sci 1998;23:360-7.

6 Wright CG, Meyerhoff WL, Halama AR. Ototoxicity of neomycin and polymyxin B following middle ear infection in the chinchilla and baboon. Am J Otol 1987;8:495-9

7 Linder TE, Zwicky S, Brandle P. Ototoxicity of ear drops: a clinical perspective. Am J Otol 1995; 16:653-7.

8 Dohar JE, Alper CM, Rose EA, Doyle WJ, Casselbrant ML, Kenna MA, et al. Treatment of chronic suppurative otitis media with topical ciprofloxacin. Ann Otol Rhinol Laryngol 1998;107:865-71.

9 Archer GL, Polk RE. Harrison's principles of internal medicine. In: Fauci AS, Braunwald E, Isselbacher KJ, Wilson JD, Martin JB, Kasper DL, et al. Treatment and prophylaxis of bacterial infections. 14th ed. New York: MacGraw-Hill, 1998:856-9.

10 Buck ML. Ciprofloxacin use in children: a review of recent findings. Pediatric Pharmacother 1998;4:12.

11 Blondeau JM, Suter ME, Borsos S, Misfeldt C. Canadian Pseudomonas aeruginosa susceptibility study from 48 medical centres: focus on ciprofloxacin. Int J Antimicrob Agents 1998;10:297-302.

12 Iaconis JP, Pitkin DH, Sheikh W, Nadler HL. Comparison of antibacterial activities of meropenem and six other antimicrobials against Pseudomonas aeruginosa isolates from North American studies and clinical trials. Clin Infect Dis 1997;24(suppl 2):191-6S.

\title{
Sources of Toxoplasma gondii infection in pregnancy
}

\section{Until rates of congenital toxoplasmosis fall, control measures are essential}

Papers p 142

BMJ 2000;321:127-8
$\mathrm{H}$ umans commonly acquire Toxoplasma gondii infection by ingesting food and water contaminated with the resistant stage of the parasite (oocyst) shed in the faeces of infected cats or by ingesting the encysted stage of the parasite (tissue cysts) in infected meat. ${ }^{1}$ Cats can rapidly shed millions of oocysts after eating rodents, birds, or other animals infected with $T$ gondii, and these oocysts can remain viable in the environment for many months. ${ }^{1}$ Toxoplasma, listeria, and salmonella are the three most important pathogens carried by food in terms of illness and death in the United States and perhaps in Europe. Pork, lamb, and mutton are the most important sources of $T$ gondii infection, along with game meats such as bear and feral swine. ${ }^{2-4}$

There is no test to distinguish infections from oocysts as opposed to tissue cysts. Therefore, epidemiological surveys remain the most useful way of assessing the relative importance of different sources of $T$ gondii infection in human beings. This approach is not so effective when subjects are chronically infected and infections might have occurred many years before. The paper by Cook et al in this issue (p 142) reports risk factors for acute toxoplasmosis in women who acquired infection during pregnancy. ${ }^{5}$ A total of 252 women with toxoplasmosis, along with 748 controls from Naples, Lausanne, Copenhagen, Oslo, Brussels, and Milan, were interviewed by telephone or in person. Overall, eating raw or undercooked beef, lamb, or other meats; contact with soil; and travel outside the country were major sources of infection. ${ }^{5}$ Surprisingly, the risk of $T$ gondii infection was increased in women who reported tasting or eating raw or undercooked beef, lamb, or game meats, but not pork. However, it is well documented that lamb and goat meat are sources of $T$ gondii. ${ }^{6}$ Finding beef as a source of infection is unexplained because $T$ gondii has never been isolated from edible beef in Europe or North America. ${ }^{1}$ Adulteration of beef by cheaper meats is not uncommon in grocery stores, and this is one possible explanation for the association of infection with beef. Further studies are needed in both beef and poultry, in live animals and retail meats, to adequately assess the role of these species in human infections.

In the past, pigs have been regarded as the most important meat source of $T$ gondii infection in humans. ${ }^{1}$ Fortunately, the prevalence of $T$ gondii in market pigs (six month old pigs) is declining drastically in Europe and North America. ${ }^{6} 7$ A higher risk of $T$ gondii in women who ate raw sausages, salami, and cured meats is easily explained because the prevalence of the organism is high in older animals; for example, it was isolated from $17 \%$ of 1000 sows from one abattoir in the United States. ${ }^{8}$ The authors point out that indoor pigs are less likely to harbour T gondii, and this is true if good biosecurity is practised. Consumers tend to thoroughly cook pork, a holdover from fears of acquiring trichinellosis. The consumption of unpasteurised milk or milk products, whether from goats, sheep, or cows, was an unexplained risk because tachyzoites, the stage most likely to be present in milk, are thought to be destroyed immediately by gastric juice. ${ }^{5}$ However, recent evidence indicates that ingested tachyzoites can cause infection. ${ }^{9}$ There has also been a case of acute toxoplasmosis in a breast fed infant. ${ }^{10}$

The association of cats and human toxoplasmosis is difficult to assess by epidemiological surveys because soil, not the cats, is the main culprit. Oocysts are not found on cat fur and are often buried in soil along with cat faeces. ${ }^{11}$ Therefore, direct contact with cats is 
irrelevant with respect to $T$ gondii transmission, and soil contact is universal and difficult to avoid.

The study by Cook et al is informative and is useful to the public health community. However, risk assessments such as this may be influenced by the small sample size and reliability of personal interviews. Therefore, additional studies of this type should be encouraged to add confidence to our understanding of risks of human exposure to $T$ gondii. At the same time, there is an urgent need to determine the prevalence of the organism in edible meats in grocery stores so that relative risks of acquiring toxoplasmosis from different types of meats can be accurately assessed. The authors rightly point out that although prevalence of $T$ gondii has declined in adult human beings and pigs by advocacy of control measures, the incidence of congenital toxoplasmosis in children has not decreased in the past decade $^{5}{ }^{712}$ Therefore, health education and control measures (eating frozen, well cooked meat, keeping cats away from pig housing) must continue.

\section{J P Dubey microbiologist}

Parasite Biology and Epidemiology Laboratory, Livestock and Poultry Sciences Institute, Agricultural Research Service, US Department of Agriculture, Building 1001, Beltsville Agricultrual Research Centre East, Beltsville, MD 20705-2350, USA
Dubey JP, Beattie CP. Toxoplasmosis of animals and man. Boca Raton, FL: CRC Press, 1988

2 Mead PS, Slutsker L, Dietz V, McCaig LF, Bresee JS, Shapiro C, et al Food-related illness and death in the United States. Emerg Infect Dis 1999;5:607-24.

3 Dubey JP, Humphreys JG, Thulliez P. Prevalence of viable Toxoplasma gondii tissue cysts and antibodies to T. gondii by various serologic tests in black bears (Ursus americanus) from Pennsylvania. J Parasito 1995;81:109-12

4 Dubey JP, Rollor EA, Smith K, Kwok OCH, Thulliez P. Low seroprevalence of Toxoplasma gondii in feral pigs from a remote island lacking cats. J Parasitol 1997;83:839-41.

5 Cook AJC, Gilbert RE, Buffolano W, Zufferey J, Petersen E, Jenum PA, et al. Sources of toxoplasma infection in pregnant women: European multicentre case-control study. BMJ 2000;321:142-7.

6 Edelhofer R. Prevalence of antibodies against Toxoplasma gondii in pigs in Austria-an evaluation of data from 1982 and 1992. Parasitol Res 1994;80:642-4.

7 Dubey JP, Weigel RM, Siegel AM, Thulliez P, Kitron UD, Mitchell MA, et al. Sources and reservoirs of Toxoplasma gondii infection on 47 swine farms in Illinois. J Parasitol 1995;81:723-9.

8 Dubey JP, Thulliez P, Powell EC. Toxoplasma gondii in Iowa sows: comparison of antibody titers to isolation of T. gondii by bioassays in mice and cats. J Parasitol 1995;81:48-53.

9 Dubey JP. Re-examination of resistance of Toxoplasma gondii tachyzoites and bradyzoites to pepsin and trysin digestion. Parasitology 1998;116: 43-50.

10 Bonametti AM, Passos JN, Koga de Silva EM, Macedo ZS. Probable transmission of acute toxoplasmosis through breast feeding. J Trop Ped 1997;43:116.

11 Dubey JP. Duration of immunity to shedding of Toxoplasma gondi oocysts by cats. J Parasitol 1995;81:410-5.

12 Smith KL, Wilson M, Hightower AW, Kelley PW, Struewing JP, Juranek DD. Prevalence of Toxoplasma gondii antibodies in US military recruits in 1989: comparison with data published in 1965. Clin Infect Dis 1996;23:1182-3.

\section{Corticosteroids in head injury}

\section{It's time for a large simple randomised trial}

$\mathrm{T}$ The global epidemic of head injuries is only just beginning. Currently over a million people die each year from brain injuries, and a similar number are disabled, often with profound effects on the quality of their lives. ${ }^{1}$ Road crashes account for most of the injuries, and car use is rapidly increasing in many countries. By 2020 road crashes will, it is estimated, have moved from ninth to third in the world ranking of disease burden as measured in disability adjusted life years, and second in developing countries. ${ }^{2}$ Identifying effective treatments for head injury is thus of global health importance.

Corticosteroids have been used to treat severe head injury for over 30 years, though recently their value has been questioned because of the failure to demonstrate effectiveness in randomised trials. ${ }^{3}$ Nevertheless, corticosteroids continue to be used widely, albeit inconsistently. Two 1996 British surveys, one of nursing staff in 39 neurosurgical intensive care units and one of medical directors in 44 neurosurgical intensive care units, found that corticosteroids were used to treat head injury in $49 \%$ and $14 \%$ of units respectively. ${ }^{45}$

If a treatment as simple and widely practicable as corticosteroids produced just a moderate benefit this would be worth while. If, for example, they reduced the absolute risk of death by $2 \%$ (say from $15 \%$ to $13 \%$ dead) and reduced the risk of permanent disability by a similar amount then treatment of 500000 patients would avoid 10000 deaths and prevent 10000 permanent disabilities. Such a benefit would be impossible to show reliably without evidence from large randomised trials.
If 10000 patients were randomly allocated to receive a corticosteroid infusion and 10000 a placebo infusion then a $2 \%$ absolute reduction in the risk of death or disability should be detectable and a $3 \%$ reduction would certainly be detectable. By contrast, a trial of only 2000 patients would probably miss such differences. Reliable refutation of benefit is of equal importance, as it would protect patients currently treated with corticosteroids from any adverse effects.

So far all the randomised trials of corticosteroids in head injury have been too small to demonstrate or refute the possibility of moderate but clinically important benefits or harm from corticosteroids: the largest included only a few hundred patients, and even in aggregate they have included only about $2000 .{ }^{6}$ As a result, the use of corticosteroids in head injury has waxed and waned over time, with extensive variations in practice.

Evidence of benefit from corticosteroids in acute spinal cord injury has renewed interest in their role in brain injury. The second US national acute spinal cord injury study (NASCIS 2) compared 24 hours of corticosteroid (methylprednisolone) with placebo in 333 patients with acute spinal cord injury. ${ }^{7}$ At six months patients who had received corticosteroids within eight hours of injury had greater improvement in motor function and in sensation to pinprick and touch. Similar results were reported in a Japanese trial of 151 patients who received the same regimen. ${ }^{7}$ More recent trials of methylprednisolone in acute spinal cord injury have indicated slightly more neurological 